Emile F. Schippers

Jimmy F. P. Berbée

Inge M. van Disseldorp

Michael I. M. Versteegh

Louis M. Havekes

Patrick C. N. Rensen

Jaap T. van Dissel

\section{Preoperative apolipoprotein CI levels correlate positively with the proinflammatory response in patients experiencing endotoxemia following elective cardiac surgery}

Received: 3 December 2007

Accepted: 24 February 2008

Published online: 12 April 2008

(C) The Author(s) 2008

E. F. Schippers $(\bullet) \cdot$ I. M. van Disseldorp •

J. T. van Dissel

Leiden University Medical Center,

Department of Infectious Diseases, C5-P42,

P.O. Box 9600, 2300 RC Leiden,

The Netherlands

e-mail: E.F.Schippers@lumc.nl

Tel.: +31-71-5262613

Fax: +31-71-5266758

J. F. P. Berbée · L. M. Havekes ·

P. C. N. Rensen

Leiden University Medical Center,

Department of General Internal Medicine,

Endocrinology and Metabolic Diseases,

P.O. Box 9600, 2300 RC Leiden,

The Netherlands

M. I. M. Versteegh

Leiden University Medical Center,

Department of Cardiothoracic Surgery,

P.O. Box 9600, 2300 RC Leiden,

The Netherlands
L. M. Havekes

Leiden University Medical Center,

Department of Cardiology,

P.O. Box 9600, 2300 RC Leiden,

The Netherlands

L. M. Havekes

TNO-Quality of Life, Department of

Biomedical Research,

Leiden, The Netherlands

\begin{abstract}
Objective: Experimental models show that apolipoprotein CI (apoCI) binds and enhances the inflammatory response to endotoxin. We studied in patients undergoing cardiopulmonary bypass surgery (CPB) and experiencing endotoxemia during reperfusion whether plasma apoCI levels correlate with the inflammatory response and perioperative cytokine release. Design: Prospective, observational, clinical cohort study. Setting: Operating room (OR) and intensive care unit (ICU) of a university hospital. Patients: One hundred fifty-nine consecutive
\end{abstract}

patients $>18$ years of age $(66 \%$ males $(n=105)$, median age 65 and 67 years for males and females, respectively) undergoing elective cardiothoracic surgery with cardiopulmonary bypass. Interventions: None. Measurements: Baseline apoCI, apoCIII, total cholesterol and triglyceride levels, and perioperative endotoxin and $\mathrm{TNF}-\alpha$ levels were determined. Results: High preoperative plasma apoCI, but not apoCIII, levels were associated $(p<0.05)$ with increased perioperative levels of TNF- $\alpha$ in patients experiencing endotoxemia. This association was not observed in patients without endotoxemia. Conclusion: High plasma apoCI is positively related to proinflammatory response in patients experiencing endotoxemia and confirms the observations in animal models.

Keywords Cardiopulmonary bypass . SIRS · Endotoxemia · Endotoxin . ApoCI $\cdot$ TNF- $\alpha$

\section{Introduction}

The host response to bacterial invasion requires recognition of pathogens. In Gram-negative bacterial infection, endotoxin (lipopolysaccharide, LPS), a component of the Gram-negative bacterial cell wall, is a powerful stimulator of the host inflammatory reaction. Endotoxin elicits this response by binding to a cell surface receptor composed of at least three distinct proteins-CD14, Toll-like receptor-4 (TLR4) and MD-2 [1, 2]—and triggers release of proinflammatory cytokines like TNF- $\alpha$.
We and others have shown that apolipoproteins modulate the host inflammatory response to endotoxin [3]. Functionally, apolipoproteins are surface proteins on circulating lipoprotein particles and regulate the metabolism and trafficking of these particles. Experimental studies have shown that apolipoproteins are involved in the modulation of inflammatory processes and protection against infections agents [4-9]. Recently, we showed that apolipoprotein CI (apoCI) binds to endotoxin and stimulates the endotoxin-induced inflammatory response by macrophages in vitro and in vivo in mice $[10,11]$. 
The apoCI-mediated enhanced anti-bacterial attack was essential to protect mice against mortality from Gramnegative bacterial sepsis. ApoCIII, which is structurally closely related to apoCI and has a similar distribution over lipoproteins, did not appear to bind endotoxin and did not alter the endotoxin-induced inflammatory response [10]. These experimental findings were further supported by a study in elderly in which high plasma apoCI levels are associated with a lower risk of mortality from infection $[12,13]$; however, the relation between plasma levels of apoCI and the inflammatory response to endotoxemia in humans has not been studied systematically.

Cardiac surgery with cardiopulmonary bypass (CPB) induces a variable systemic inflammatory response that may progress from a relatively mild to a severe and potentially life-threatening situation [14]. Previously, we demonstrated an association between the occurrence of perioperative endotoxemia and the postoperative inflammatory response, suggesting endotoxin as etiologic factor in the cytokine release in patients undergoing CPB [15]. Splanchnic ischemia and gut reperfusion injury occurs frequently during the procedure and subsequent disturbance in gut barrier function, marked by translocation of endotoxin to the systemic circulation, has been documented [14, 16, 17].

We postulate that apoCI is a significant determinant of the endotoxin-induced inflammatory response in these patients and assessed the relation between preoperative apoCI plasma levels and the perioperative cytokine activation in patients experiencing endotoxemia. To indicate that a potential relation between apoCI and TNF- $\alpha$ is not merely a reflection of lipid or apolipoprotein levels, we compare our findings with those on total cholesterol, triglycerides and apoCIII.

\section{Materials and methods}

The study was performed at the Leiden University Medical Center, an 800-bed secondary and tertiary referral hospital. To be eligible for enrolment, patients had to be aged 18 years or older and being scheduled for elective cardiac surgery with cardiopulmonary bypass between 1 July 1998 and 30 December 1999. We obtained institutional approval from the local medical ethics committee (protocol no. P168/96). Each patient gave a written, informed consent. One hundred fifty-nine consecutive patients undergoing elective cardiac surgery with CPB were studied, which has been extensively described previously $[18,19]$.

\section{Sample collection}

Briefly, blood samples were collected from each patient before anaesthetic induction (time point 1), on aorta declamping (time point 2), 30 min into body reperfusion (i.e. $30 \mathrm{~min}$ after termination of extra corporal perfusion, time point 3 ), and at ICU admission (approximately $2 \mathrm{~h}$ after surgery, time point 4$)[18,19]$.

\section{Endotoxin and TNF-alpha measurements}

Blood for endotoxin determination was collected in pyrogen-free tubes and platelet-rich plasma was prepared by centrifugation. Endotoxin was determined by a quantitative photometric assay with end-point measurement. The assay's lower detection limit for endotoxin was $3.0 \mathrm{pg} / \mathrm{ml}$ [20]. Endotoxin concentrations $\geq 5 \mathrm{pg} / \mathrm{ml}$ were considered to indicate endotoxemia $[20,21]$. Blood for determination of TNF-a was collected in pyrogen-free ethylenediaminetetraacetic acid (EDTA) tubes and immersed in ice. Plasma was prepared by centrifugation at $3000 \mathrm{~g}$ for $5-10 \mathrm{~min}$ at $4^{\circ} \mathrm{C}$ and stored at $-70^{\circ} \mathrm{C}$. Tumor necrosis factor (TNF)- $\alpha$ concentrations were determined with a standard ELISA technique. The lower detection limit for TNF- $\alpha$ was $0.1 \mathrm{pg} / \mathrm{ml}[18,19]$.

Plasma total cholesterol, triglycerides and apolipoprotein measurements

Plasma apoCI and apoCIII levels were assayed using sandwich ELISAs specific for human apoCI [13] and apoCIII [22], as described. For both ELISAs the inter-assay coefficient of variance is typically less than $10 \%$, while the intra-assay coefficient of variance is typically less than $7 \%$ (apoCI) and 5\% (apoCIII). No cross-reactivity of the used antibodies is observed with other apolipoproteins. Total cholesterol and triglycerides levels were determined using commercially available kits (Roche Diagnostics Cholesterol Reagent and Triglyceride Reagent, respectively; Roche Diagnostics, Almere, The Netherlands).

\section{Analysis of data}

Correlations were assessed non-parametrically using Spearman correlation test, comparisons between groups were made using Kruskal-Wallis test, individual groups were compared by the Mann-Whitney $U$-test, unless indicated otherwise. Statistical significance was tested two tailed, with $\alpha$ set at 0.05 .

\section{Results}

Patient characteristics

We studied 159 consecutive patients undergoing elective cardiothoracic surgery with $\mathrm{CPB}$. The patient charac- 
teristics have been described previously [18]. Surgical procedures were extensive; 19 patients (12\%) underwent coronary artery bypass surgery $(\mathrm{CABG})$ combined with valve replacement, 87 patients $(55 \%)$ underwent $\mathrm{CABG}$ only and 48 patients $(30 \%)$ underwent valve replacement only (Table 1). Five patients (3\%) underwent other surgical procedures, mainly aortic surgery (Table 1 ).

Correlation between preoperative cholesterol, triglyceride, apoCI and apoCIII levels and perioperative TNF-alpha release

Data on cholesterol, triglycerides, apoCI and apoCIII were available for 148 patients. Perioperative TNF- $\alpha$ levels were available for 112, 106, 108 and 110 patients for time points 1, 2, 3 and 4, respectively. Endotoxin levels for time points 2 and/or 3 were available for 143 patients.

The relationship between perioperative endotoxemia and cytokine release in these 159 patients has been described previously [18, 19]. Briefly, we found that perioperative endotoxemia was positively correlated with subsequent TNF- $\alpha$ release. In the current analysis we assessed correlations between preoperative plasma levels of cholesterol, triglyceride, apoCI and apoCIII with perioperative TNF- $\alpha$ plasma concentrations.

In patients with significant endotoxemia (endotoxin level $\geq 5 \mathrm{pg} / \mathrm{ml}$ at time points 2 and/or $3 ; n=85$ ) we observed a significant correlation between preoperative apoCI and cholesterol levels and TNF- $\alpha$ concentrations at time points 2-4 (the latter for apoCI only), whereas no such correlation could be observed with preoperative apoCIII and triglyceride levels (Table 2). No significant correlations were observed in patients without endotoxemia as defined by an endotoxin level $<5 \mathrm{pg} / \mathrm{ml}$ at both time points 2 and $3(n=58$; Table 2$)$.

To visualize the apoCI data we split the endotoxemiapositive and endotoxemia-negative patients into three
Table 1 Characteristics of 159 patients undergoing elective cardiac surgery with cardiopulmonary bypass. $C A B G$, coronary artery bypass graft; $I C U$, intensive care unit; $M O F$, multiple organ dysfunction

\begin{tabular}{lc}
\hline Variables & Values \\
\hline Preoperative data & \\
Age (years) & $65(56-72)$ \\
Weight $(\mathrm{kg})$ & $78(68-88)$ \\
Males, $n(\%)$ & $106(67)$ \\
Active smoker, $n(\%)$ & $31(20)$ \\
Diabetes (types I and II), $n(\%)$ & $19(12)$ \\
ASA score, $n(\%)$ & \\
$\leq 2$ & $12(8)$ \\
3 & $88(55)$ \\
$\geq 4$ & $9(6)$ \\
Unknown & $50(32)$ \\
Type of operation & $87(55)$ \\
CABG only, $n(\%)$ & $48(30)$ \\
Valve replacement only, $n(\%)$ & $19(12)$ \\
CABG and valve replacement, $n(\%)$ & $5(3)$ \\
Other, $n(\%)$ & \\
Perioperative data & $240(183-285)$ \\
Operation time (min) & $116(85-141)$ \\
Perfusion time (min) & $71(49-90)$ \\
Aorta clamp time (min) & $29(28-31)$ \\
Lowest temperature $\left({ }^{\circ} \mathrm{C}\right)$ & $1(1-2)$ \\
Postoperative data & $3(2-5)$ \\
Days on ventilator & $6(3.8)$ \\
ICU stay (days) & $11(9-15)$ \\
MOF, $n(\%)$ & $14(9)$ \\
Hospital stay (days) &
\end{tabular}

Median values and interquartile range in parentheses

equally large groups (tertiles) according to their preoperative plasma cholesterol, triglyceride, apoCI and apoCIII levels (tertiles), and plotted these against the TNF- $\alpha$ concentration at the four time points. High preoperative apoCI levels were markedly associated with increased TNF- $\alpha$ concentration at time points $2-4$ in endotoxemia-positive
Table 2 Correlation coefficient between preoperative lipid/ apolipoprotein level and TNF- $\alpha$ concentration at consecutive time points perioperatively. Time points 2-4 correspond with aorta declamping, 30 min into body reperfusion (i.e. $30 \mathrm{~min}$ after termination of extra-corporal perfusion) and admission to the ICU (approximately $2 \mathrm{~h}$ after surgery), respectively. Significant correlations were observed between cholesterol and TNF- $\alpha$ in endotoxemia-positive patients at time points 2 and 3 , and ApoCI and TNF- $\alpha$ in endotoxemia-positive patients at time points $2-4$

\begin{tabular}{lccc}
\hline Variables & Time point 2 & Time point 3 & Time point 4 \\
\hline Endotoxemia positive & $n=63$ & $n=65$ & $n=65$ \\
Cholesterol & $0.434^{* * *}$ & $0.259^{*}$ & 0.174 \\
Triglycerides & 0.133 & 0.236 & 0.237 \\
ApoCI & $0.305^{*}$ & $0.351^{* *}$ & $0.425^{* * *}$ \\
ApoCIII & -0.106 & 0.062 & 0.077 \\
Endotoxemia negative & $n=36$ & $n=35$ & $n=35$ \\
Cholesterol & 0.186 & 0.074 & -0.329 \\
Triglycerides & 0.214 & 0.037 & -0.153 \\
ApoCI & 0.299 & 0.157 & -0.330 \\
ApoCIII & -0.161 & -0.060 & -0.068 \\
\hline
\end{tabular}

${ }^{*} p<0.05,{ }^{* *} p<0.01,{ }^{* * *} p<0.001$ (Spearman correlation test) 
Fig. 1 Perioperative TNF- $\alpha$ concentration in patients experiencing endotoxemia (a) and those without (b) according to preoperative apoCI and apoCIII tertiles $(1=$ lowest tertile, $2=$ intermediate tertile, $3=$ highest tertile). The $p$-values were calculated using KruskalWallis test
Endotoxemia-positive patients

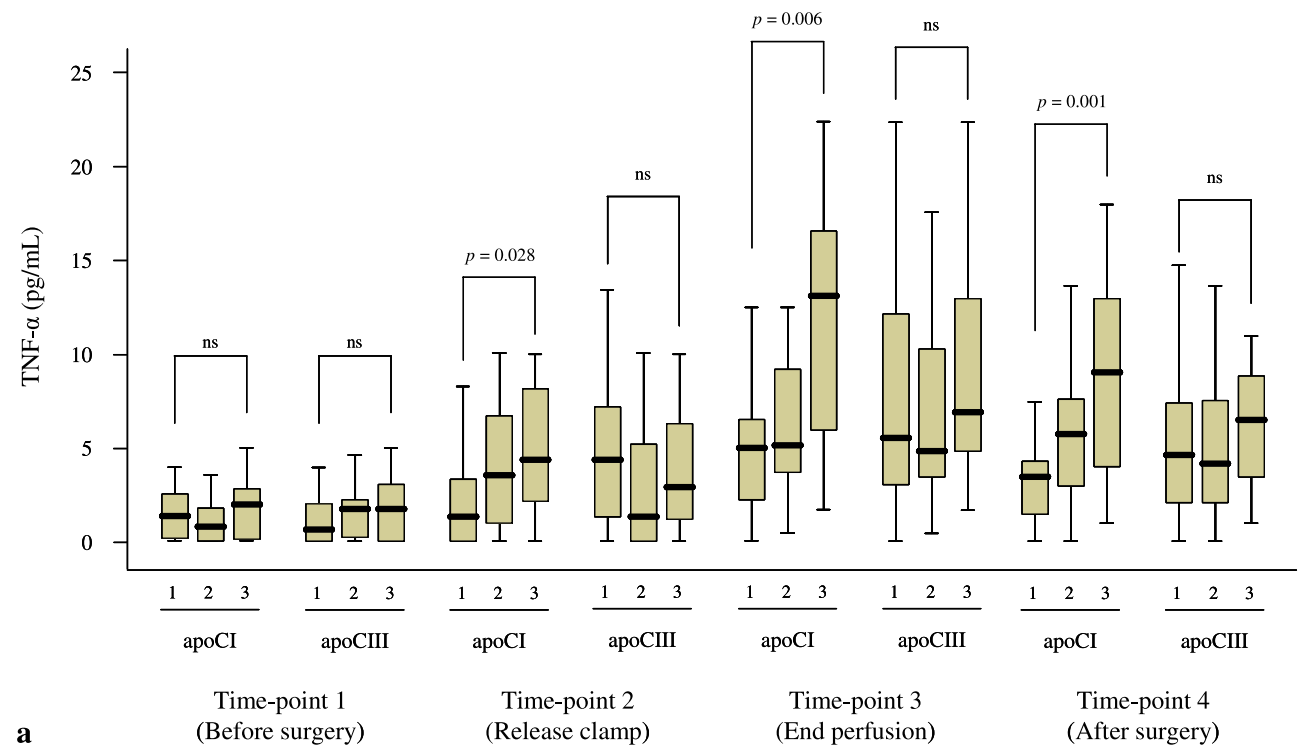

Endotoxemia-negative patients

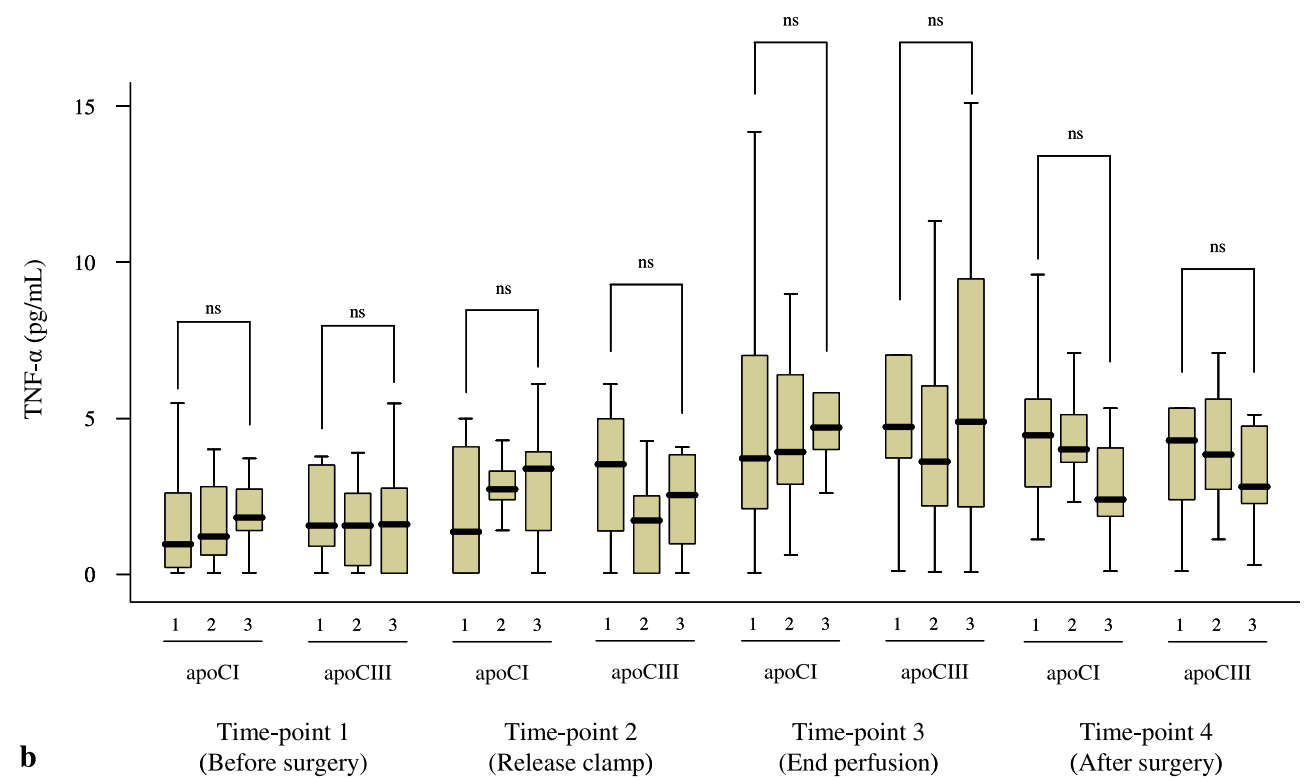

patients (Fig. 1a), but not in endotoxemia-negative patients (Fig. 1b). No associations were found with preoperative apoCIII levels (Fig. 1).

\section{Discussion}

The main finding of the present study is that in patients undergoing cardiac surgery with cardiopulmonary bypass (CPB) high plasma apoCI levels are correlated with an enhanced proinflammatory response in patients experiencing endotoxemia as compared with patients without endotoxemia. This characteristic is not shared among all apolipoproteins or lipids, since this observation did not hold for apoCIII or triglyceride levels and TNF- $\alpha$ levels. Although at some time points a correlation with cholesterol was found as well, these correlations are less pronounced and consistent. On the contrary, the proinflammatory response in patients without endotoxemia was not correlated with apoCI levels. This finding suggests a role for apoCI in enhancing the host response to bacterial products involved in pathogen recognition.

To our knowledge, this is the first study indicating this relationship between plasma levels of apoCI and the 
inflammatory response to endotoxemia in humans in vivo. This finding is relevant for understanding mechanisms by which the host mounts a swift response to invading micro-organisms in the early phase of infection. An early proinflammatory cytokine response to invading pathogens is crucial for containment and elimination of the bacteria, whereas in a latter phase a high proinflammatory response is often harmful and may lead to tissue damage and organ failure. In Gram-negative bacterial infection, endotoxin (LPS) is a powerful stimulator of the host inflammatory reaction through activation of the TLR4 signaling pathway.

Previously, we demonstrated in mice that apoCI binds to endotoxin and enhances the endotoxin-induced proinflammatory response, thereby invigorating host response mechanisms. Based on our current findings, apoCI may also enhance the endotoxin-induced proinflammatory response in humans. Moreover, combined with our previous observation that subjects with high plasma apoCI levels at baseline are less prone to mortality from infection during a 5-year follow-up [13], these findings support a beneficial role for apoCI in the handling of infections in humans. High plasma apoCI levels may protect against bacterial invasion by enhancing the proinflammatory response directed towards endotoxin, in line with our experimental studies.

With respect to this study and methodology, several issues need to be considered. The cut-off level of endotoxin concentration indicating significant endotoxemia is somewhat arbitrary; however, it is based on previous studies and has been prospectively evaluated [20, 21]. Furthermore, the criterion used is substantiated by our previous findings in these patients, in which we observed significantly higher cytokine concentrations in patients with endotoxemia, according to this criterion, as compared with those without. These clinical data confirm the rationale to dichotomise the group according to endotoxemia. In the current study we assessed TNF- $\alpha$ as measure of the proinflammatory cytokine response. TNF- $\alpha$ plays a central role in the proinflammatory cytokine cascade. The findings would suggest a similar elevation of other proinflammatory cytokines (i.e. IL-6, IL-1), although we did not measure these mediators here. An other limitation of our study is that the findings cannot be directly extrapolated to patients with Gram-negative infection: our model is not an infection model in the sense of live, multiplicating micro-organisms invading the host. However, naturally occurring endotoxemia mimics invasive Gram-negative infection and enabled us to study the in vivo interaction between microbial products and the host. Furthermore, our study was small, making the power to detect possible differences in clinical outcome small. Further prospective studies are now underway to make these analyses possible.

Acknowledgements. We thank the nursing staff of the cardiothoracic intensive care unit for their kind cooperation. This study was supported in part by a grant (\#28-2875,23) of ZorgOnderzoek Nederland, formerly the Dutch Foundation for Preventive Medicine PraeventieFonds, Netherlands Organization for Scientific Research (NWO VIDI 917-36-351 to PCNR), by the Leiden University Medical Center (Gisela Thier Fellowship to PCNR) and by the Netherlands Heart Foundation (NHS 2005B226 to PCNR).

Open Access. This article is distributed under the terms of the Creative Commons Attribution Noncommercial License which permits any noncommercial use, distribution, and reproduction in any medium, provided the original author(s) and source are credited.

\section{References}

1. Hoshino K, Takeuchi O, Kawai T, Sanjo H, Ogawa T, Takeda Y, Takeda K, Akira S (1999) Cutting edge: toll-like receptor 4 (TLR4)-deficient mice are hyporesponsive to lipopolysaccharide: evidence for TLR4 as the LPS gene product. J Immunol 65:3749-3752

2. Moore KJ, Andersson LP, Ingalls RR, Monks BG, Li R, Arnaout MA, Golenbock DT, Freeman MW (2000) Divergent response to LPS and bacteria in CD14-deficient murine macrophages. J Immunol 165:4272-4280

3. Berbee JF, Havekes LM, Rensen PC (2005) Apolipoproteins modulate the inflammatory response to lipopolysaccharide. J Endotoxin Res 11:97-103

4. Feingold KR, Grunfeld C (1997) Lipoproteins: Are they important components of host defense? Hepatology 26:1685-1686
5. Rensen PC, Oosten M, Bilt E, Eck M, Kuiper J, Berkel TJ (1997) Human recombinant apolipoprotein $\mathrm{E}$ redirects lipopolysaccharide from Kupffer cells to liver parenchymal cells in rats in vivo. J Clin Invest 99:2438-2445

6. van den Elzen EP, Garg S, Leon L, Brigl M, Leadbetter EA, Gumperz JE, Dascher CC, Cheng TY, Sacks FM, Illarionov PA et al. (2005) Apolipoprotein-mediated pathways of lipid antigen presentation. Nature 437:906-910

7. de Bont N, Netea MG, Demacker PN, Verschueren I, Kullberg BJ, van Dijk KW, van der Meer JW, Stalenhoef AF (1999) Apolipoprotein E knock-out mice are highly susceptible to endotoxemia and Klebsiella pneumoniae infection. J Lipid Res 40:680-685
8. Ma J, Liao XL, Lou B, Wu MP (2004) Role of apolipoprotein A-I in protecting against endotoxin toxicity. Acta Biochim Biophys Sin (Shanghai) 36:419-424

9. van Oosten M, Rensen PC, van Amersfoort ES, van Eck M, van Dam AM, Breve JJ, Vogel T, Panet A, van Berkel TJ, Kuiper J (2001) Apolipoprotein $\mathrm{E}$ protects against bacterial lipopolysaccharide-induced lethality. A new therapeutic approach to treat Gram-negative sepsis. J Biol Chem 276:8820-8824

10. Berbee JF, van der Hoogt CC, Kleemann R, Schippers EF, Kitchens RL, van Dissel JT, Bakker-Woudenberg IA, Havekes LM, Rensen PC (2006) Apolipoprotein CI stimulates the response to lipopolysaccharide and reduces mortality in Gram-negative sepsis. FASEB J 20:2162-2164 
11. Berbee JF, Schippers EF, van der Hoogt CC, Kitchens RL, van Dissel JT, Bakker-Woudenberg IA, Havekes LM, Rensen PC (2006) Apolipoprotein CI stimulates the inflammatory response to lipopolysaccharide in mice and humans. Atherosclerosis S7:227

12. Westerterp M, Berbee JF, Pires NM, van Mierlo GJ, Kleemann R, Romijn JA, Havekes LM, Rensen PC (2007) Apolipoprotein C-I is crucially involved in lipopolysaccharideinduced atherosclerosis development in apolipoprotein E-knockout mice. Circulation 116:2173-2181

13. Berbee JF, Mooijaart SP, de Craen AJ, Havekes LM, van Heemst D, Rensen PC, Westendorp RG (2008) Plasma apolipoprotein CI protects against mortality from infection in old age. J Gerontol A Biol Sci Med Sci 63:122-126

14. Riddington DW, Venkatesh B, Boivin CM, Bonser RS, Elliott TS, Marshall T, Mountford PJ, Bion JF (1996) Intestinal permeability, gastric intramucosal $\mathrm{PH}$, and systemic endotoxemia in patients undergoing cardiopulmonary bypass. J Am Med Assoc 275:1007-1012
15. Bouter H, Schippers EF, Luelmo SA, Versteegh MI, Ros P, Guiot HF, Frolich M, van Dissel JT (2002) No effect of preoperative selective gut decontamination on endotoxemia and cytokine activation during cardiopulmonary bypass: a randomized, placebo-controlled study. Crit Care Med 30:38-43

16. Oudemans-van Straaten HM, Jansen PG, Hoek FJ, van Deventer SJ, Sturk A, Stoutenbeek CP, Tytgat GN, Wildevuur CR, Eysman L (1996) Intestinal permeability, circulating endotoxin, and postoperative systemic responses in cardiac surgery patients. J Cardiothorac Vasc Anesth 10:187-194

17. Rossi M, Sganga G, Mazzone M, Valenza V, Guarneri S, Portale G, Carbone L, Gatta L, Pioli C, Sanguinetti M et al. (2004) Cardiopulmonary bypass in man: role of the intestine in a selflimiting inflammatory response with demonstrable bacterial translocation. Ann Thorac Surg 77:612-618

18. Schippers EF, van 't Veer C, van Voorden S, Martina CA, le Cessie S, van Dissel JT (2004) TNF-alpha promoter, Nod2 and Toll-like receptor-4 polymorphisms and the in vivo and ex vivo response to endotoxin. Cytokine 26:16-24
19. Schippers EF, van 't Veer C, van Voorden JB, Huizinga T, le Cessie S, van Dissel JT (2005) IL-10 and toll-like receptor-4 polymorphisms and the in vivo and ex vivo response to endotoxin. Cytokine 29:215-228

20. van Deventer SJ, Buller HR, ten Cate JW, Sturk A, Pauw W (1988) Endotoxaemia: an early predictor of septicaemia in febrile patients. Lancet 340:605-609

21. van Langevelde P, Joop K, van Loon J, Frolich M, Groeneveld PH, Westendorp R G, van Dissel JT (2000) Endotoxin, cytokines, and procalcitonin in febrile patients admitted to the hospital: identification of subjects at high risk of mortality. Clin Infect Dis 31:1343-1348

22. Schaap FG, Nierman MC, Berbee JF, Hattori H, Talmud PJ, Vaessen SF, Rensen PC, Chamuleau RA, Kuivenhoven JA, Groen AK (2006) Evidence for a complex relationship between ApoA-V and ApoC-III in patients with severe hypertriglyceridemia. J Lipid Res 47:2333-2339 